\title{
PENGARUH PROGRAM KESEJAHTERAAN KARYAWAN DAN DISIPLIN KERJA TERHADAP PENINGKATAN PRODUKTIVITAS KERJA KARYAWAN RSUP SANGLAH DENPASAR-BALI
}

\author{
Komang Ary Pratiwi ${ }^{1}$, Ni Luh W.Sayang Telagawathi ${ }^{2}$, Ni Luh Putu Erma \\ Mertaningrum $^{3}$, Made Putri Ariasih ${ }^{4}$ \\ ${ }^{1}$ Manajemen, Universitas Hindu Indonesia, Denpasar \\ 2 Manajemen, Universitas Pendidikan Ganesha, Singaraja \\ ${ }^{3}$ Manajemen, Sekolah Tinggi IImu Sosial dan Politik Wira Bhakti, Denpasar \\ ${ }^{4}$ Manajemen, Universitas Tabanan, Tabanan \\ e-mail : arypratiwikm@gmail.com , gemilangsuryawan@gmail.com , \\ ermamertaningrum@gmail.com, putriariasih@gmail.com
}

\begin{abstract}
Abstrak
Dalam mewujudkan Visi dan Misi Rumah Sakit Umum Pusat (RSUP) Sanglah Denpasar, peranan sumber daya manusia memegang peranan penting demi menunjang kemajuan rumah sakit tersebut. Oleh karena itu sudah seharusnya sumber daya manusia yang ada diperlakukan secara adil dan layak dengan memberikan kesejahteraan melalui pemberian tunjangan atau fasilitas lainnya, sehingga mereka dapat menjadi tenaga kerja yang profesional dan disiplin serta mempunyai produktivitas kerja yang tinggi. Penelitian yang dilakukan di RSUP Sanglah Denpasar adalah bertujuan untuk mengetahui pengaruh program kesejahteraan karyawan dan Disiplin kerja Terhadap Peningkatan Produktivitas Kerja Karyawan RSUP Sanglah Denpasar

Alat analisis data yang digunakan pada penelitian ini adalah Regresi Linier Berganda. Hasil penelitian membuktikan bahwa Program Kesejahteraan Karyawan dan Disiplin Kerja berpengaruh positif signifikan terhadap Peningkatan Produktivitas Kerja Karyawan RSUP Sanglah Denpasar. Variabel yang paling berpengaruh dominan terhadap Peningkatan produktivitas kerja adalah Variabel Disiplin Kerja.
\end{abstract}

Kata Kunci : Program Kesejahteraan Karyawan, Disiplin kerja, dan Produktivitas kerja

\section{Abstract}

In realizing the Vision and Mission of the Sanglah Central General Hospital (RSUP) Denpasar, the role of human resources plays an important role in supporting the construction of the hospital. Therefore, it is necessary to have human resources that are approved and feasible by providing assistance funds or other facilities, so that they can become professional and disciplined workforce and provide high work productivity. The research carried out at RSUP Sanglah Denpasar was to study the effect of employee welfare programs and work discipline on the Increased Work Productivity of RSUP Sanglah Denpasar Employees.

The data analysis tool used in this study is Multiple Linear Regression. The results of the study prove that the Employee Welfare Program and Work Discipline have a significant positive effect on the Increased Employment Productivity of RSUP Sanglah Denpasar. The variable which has the most dominant influence on increasing work productivity is the Work Discipline Variable.

Keywords : Employee Welfare Program, Work Discipline, Work Productivity

\section{PENDAHULUAN}

\section{A. Latar Belakang}

Rumah sakit adalah sebuah institusi perawatan kesehatan profesional yang pelayanannya disediakan oleh sumber daya manusia yang ahli di bidangnya masing-masing yaitu terdiri dari tenaga medis (dokter, perawat, dan tenaga ahli kesehatan lainnya) dan tenaga non medis (bagian administratsi rumah sakit dan lainnya). Sumber daya manusia 
memegang peranan penting dalam mewujudkan visi dan misi yang ditetapkan oleh rumah sakit, serta diharapkan dapat memberikan pelayanan kesehatan secara maksimal. Sumber Daya Manusia itu sendiri merupakankemampuan terpadu dari daya pikir dan daya fisik yang dimiliki individu. Perilaku dan sifatnya ditentukan oleh keturunan dan lingkungannya, sedangkan prestasikerjanya dimotivasi oleh keinginan untuk memenuhi kepuasannya (Malayu, 2018).

Rumah Sakit berskala internasionaldan merupakan rumah sakit rujukan terbesar di Bali adalah RSUP Sanglah Denpasar. RSUP Sanglah Denpasar senantiasa dituntut memberikan jasa pelayanan kepadamasyarakat secara maksimal dan berkualitas. Agar dapat menyediakan pelayanan secara maksimal serta berkualitas, Sumber DayaManusia yang bergerak di dalamnya baik itu tenaga medis dan tenaga non medis pun dituntut harus mempunyai disiplin kerja yang tinggi, dan pihak manajemen rumah sakit juga dapat memberikan kesejahteraan pada karyawannya melalui pemberian tunjangan atau fasilitas lainnya demi peningkatan produktivitas kerja karyawan bersangkutan.Program kesejahteraan karyawan dan disiplin kerja yang tinggi penting bagi suatu perusahaan. Dengan adanya program kesejahteraan karyawan dan kedisiplinan tersebut diharapkan sebagian besar dari peraturan dapat ditaati oleh sebagian besar karyawan, serta pekerjaan pun dapat dilakukan seefektif dan seefisien mungkin. Namun menurut Cecilia et al. (2015), secara parsial Disiplin kerja tidak berpengaruh signifikan terhadap Produktivitas kerja. Sedangkan menurut Saleh et al (2018), Disiplin kerja berpengaruh positif dan signifikan terhadap Produktivitas kerja. Hubungan kesejahteraan karyawan dengan kedisiplinan sangat erat, karena untuk menegakkan kedisiplinan tidak hanya dengan peringatan saja, tetapi perlu imbalan, berupa tingkat kesejahteraan yang cukup (Harliawan et al., 2017). Salah satu caranya adalah dengan memberikan gaji/upah yang sesuai, tunjangan-tunjangan seperti tunjangan kesehatan berupa asuransi kesehatan serta berbagai fasilitas lainnya.Harliawan et al. (2017) dan Purba (2018) menyatakan bahwa Program kesejahteraan karyawan berpengaruh positif dan signifikan terhadap Produktivitas kerja karyawan. Sedangkan menurut Lukitasari (2016), menyatakan bahwa Program kesejahteraan karyawan terutama pada indikator jaminan sosial tidak berpengaruh signifikan terhadap peningkatan produktivitas kerja karyawannya.

RSUP Sanglah Denpasarperlumelakukan penilaian terhadap produktivitas kerja karyawannya masing-masing.Karena apabila produktivitas kerja karyawan baik dalam pemberian pelayananmaka konsumen selaku pengguna jasa pelayanan kesehatan akan merasa puas,sebab dalam proses konsumsi, munculnya kepuasan konsumen ditentukan olehpengguna jasa bukan penyedia jasa, karena konsumen yang dapat menentukan apakah jasa yang diberikan memuaskan atau mengecewakan. Produktivitas kerja adalah perbandingan antara output dengan input, di mana output-nya harus mempunyai nilai tambah dan teknik pengerjaannya yang lebih baik (Malayu, 2018). Berdasarkan Hal tersebut, Penulis terdorong untuk menganalisis masalah tersebut sebagai pembahasan dalam penelitian dengan judul "Pengaruh Program Kesejahteraan Karyawan Dan Disiplin Kerja Terhadap Peningkatan Produktivitas Kerja Karyawan Rumah Sakit Umum Pusat Sanglah Denpasar-Bali”.

\section{B. Rumusan Masalah}

Berdasarkan latar belakang masalah yang telah diuraikan, maka peneliti mengambil rumusan masalah sebagai berikut:

1. Apakah Program Kesejahteraan Karyawan berpengaruh signifikan terhadap peningkatan produktivitas kerja karyawan di RSUP Sanglah Denpasar-Bali?

2. Apakah Disiplin Kerja berpengaruh signifikan terhadap peningkatan produktivitas kerja karyawan di RSUP Sanglah Denpasar-Bali?

3. Faktor manakah yang paling berpengaruh terhadap peningkatan produktivitas kerja karyawan di RSUP Sanglah Denpasar-Bali? 


\section{Tujuan Penelitian}

Tujuan dilaksanakannya penelitian ini adalah :

1. Untuk mengetahui apakah program kesejahteraan karyawan berpengaruh signifikan terhadap peningkatan produktivitas kerja karyawan di RSUP Sanglah Denpasar-Bali.

2. Untuk mengetahui apakah disiplin kerja berpengaruh signifikan terhadap peningkatan produktivitas kerja karyawan di RSUP Sanglah Denpasar-Bali.

3. Untuk mengetahui faktor yang paling berpengaruh terhadap peningkatan produktivitas kerja karyawan di RSUP Sanglah Denpasar-Bali.

\section{Batasan Masalah}

Batasan masalah dimaksudkan adalah untuk memudahkan analisa selanjutnya dan mempersiapkan segala sesuatu yang dibutuhkan dalam rangka pemecahan masalah. Maka dari itu, dalam penelitian ini penulis membatasi masalah, yaitu :

1. Masalah yang diteliti adalah pengaruh program kesejahteraan karyawan dan disiplin kerja terhadap peningkatan produktivitas kerja karyawan RSUP Sanglah Denpasar-Bali.

2. Obyek penelitian adalah karyawan non medis RSUP Sanglah Denpasar-Bali.

\section{E. Landasan Teori \\ Program Kesejahteraan Karyawan}

Setiap perusahaan/organisasi pasti akan selalu mempertahankan sumber daya manusia yang dimilikinya. Perusahaan akan membina dan mengembangkan karier karyawannya, sehingga karyawan-karyawan tersebut menjadi sumber daya manusia perusahaan yang mempunyai disiplin kerja yang tinggi sehingga produktivitas kerja pun akan semakin meningkat. Untuk itu, mempertahankan karyawan yang mempunyai disiplin kerja tinggi sehingga dapat meningkatkan produktivitas kerjanya dalam pencapaian tujuan perusahaan, maka cara yang digunakan adalah dengan memberikan kesejahteraan pada karyawan dalam wujud program yang harus dilaksanakan, dimana program ini disebut program kesejahteraan karyawan.Menurut Drs.H.Malayu S.P. Hasibuan (2018), tujuan adanya program kesejahteraan karyawan adalah untuk mempertahankan dan memperbaiki kondisi fisik dan mental karyawan agar produktivitas kerjanya meningkat.Program kesejahteraan karyawan merupakan layanan pekerja mencakup keuntungan yang beraneka ragam yang diberikan oleh perusahaan kepada para pekerja disamping upah dan gaji (Manullang, 2015). Sedangkan pengertian karyawan adalah setiap orang yang bekerja dengan menjual tenaganya (fisik dan pikiran) kepada suatu perusahaan dan memperoleh balas jasa sesuai dengan peraturan dan perjanjian (Malayu, 2018).

Berdasarkan pengertian diatas, dapat dikatakan bahwa program kesejahteraan karyawan adalah bentuk dari keseluruhan program yang diberikan oleh perusahaan atau instansi dalam hal ini yaitu RSUP Sanglah Denpasar kepada para karyawannya selama masa pengabdiannya. Bentuk program kesejahteraan karyawan yang diberikan Rumah Sakit Umum Pusat Sanglah pada karyawannya, beberapa diantaranya yaitu dilihat dari segi ekonomis adanya pemberian tunjangan pensiun, pakaian dinas, tunjangan hari raya, upah/gaji. Dilihat dari segi fasilitas, tersedianya kantin, tempat sembahyang, terdapatnya pendidikan berupa pemberian seminar atau beasiswa pendidikan bagi karyawan berprestasi, pemberian cuti pada karyawan untuk tidak bekerja dalam jangka waktu tertentu, serta diadakannya kegiatan olahraga setiap jumat pagi di areal parkir Rumah Sakit Umum Pusat Sanglah. Dilihat dari pelayanan kesehatan yaitu adanya pemberian tunjangan kesehatan berupa pemberian asuransi kesehatan pada karyawan.

\section{Manfaat Program Kesejahteraan Karyawan}

Diselenggarakan suatu program haruslah diseimbangkan dengan suatu manfaat. Bagaimanapun perusahaan selalu menginginkan agar setiap program yang dibuatnya dapat mendatangkan keuntungan serta dapat dipertanggung jawabkan.Menurut 
Drs.H.Malayu S.P. Hasibuan (2018), manfaat diberikannya program kesejahteraan pada karyawan adalah :

a. Untuk meningkatkan kesetiaan dan keterikatan karyawan kepada perusahaan

b. Memberikan ketenangan dan pemenuhan kebutuhan bagi karyawan beserta keluarganya

c. Memotivasi gairah kerja, disiplin, dan produktivitas kerja karyawan

d. Menurunkan tingkat absensi karyawan

e. Menciptakan lingkungan dan suasana kerja yang baik serta nyaman

f. Membantu lancarnya pelaksanaan pekerjaan untuk mencapai tujuan

g. Memelihara kesehatan dan meningkatkan kualitas karyawan dalam bekerja

h. Mengurangi kecelakaan dan kerusakan peralatan perusahaan

\section{Disiplin Kerja}

Kedisiplinan menurut Drs.H.Malayu S.P. Hasibuan (2018) adalah kesadaran dan kesediaan seseorang menaati semua peraturan perusahaan dan norma-norma sosial yang berlaku. Sedangkan kesadaran adalah sikap seseorang yang secara sukarela menaati semua peraturan dan sadar akan tugas dan tanggung jawabnya.Jadi orang bersangkutan akan mematuhi/mengerjakan semua tugasnya dengan baik, bukan atas paksaan.Menurut Manullang (2015), Disiplin kerja adalah melakukan apa yang sudah disetujui bersama antara pimpinan dengan para pekerja, baik persetujuan tertulis, lisan atau berupa peraturan atau kebiasaan. Disiplin sangat penting karena suatu usaha tidak akan mengalami kemajuan tanpa adanya disiplin dari pihak atasan ataupun bawahan.

\section{Faktor-faktor Yang Mempengaruhi Disiplin Kerja Karyawan}

Menurut Radito (2016), menyatakan bahwa faktor-faktor yang mempengaruhi disiplin kerja karyawan adalah :

a. Motivasi

b. Pendidikan dan Pelatihan

c. Kepemimpinan

d. Kesejahteraan

e. Penegakan disiplin lewat hukum

\section{Produktivitas Kerja}

Menurut Drs.H.Malayu S.P. Hasibuan (2018), produktivitas kerja adalah perbandingan antara output dengan input, dimana output-nya harus mempunyai nilai tambah dan teknik pengerjaannya yang lebih baik. Atas dasar rumusan tersebut, maka Drs.H.Malayu S.P. Hasibuan selanjutnya menyusun suatu rumus bahwa produktivitas kerja (PK) adalah :

$$
\mathrm{PK}=\underset{\text { Input }}{\text { Output }}=\underline{\mathrm{O}}
$$

Keterangan rumus :

Output $(\mathrm{O})$ = hasil suatu kegiatan/usaha baik dalam rupiah maupun dalam satuan unit

Input (I) = tenaga kerja atau karyawan yang diukur dalam satuan waktu (perjam, hari, minggu, atau bulan) ataupun sejenisnya.

\section{Pengaruh Program Kesejahteraan Karyawan dan Disiplin Kerja Terhadap Peningkatan Produktivitas Kerja Karyawan}

Pemberian kesejahteraan pada karyawan dapat mempengaruhi disiplin kerja karyawan. Pada kenyataannya, pemberian program kesejahteraan memang sering mempengaruhi kualitas kerja dari karyawan bersangkutan.Hubungan kesejahteraan karyawan dengan kedisiplinan sangat erat, karena untuk menegakkan kedisiplinan tidak hanya dengan peringatan-peringatan, tetapi perlu imbalan, berupa tingkat kesejahteraan yang cukup (Radito, 2016). Salah satu caranya adalah dengan memberikan gaji/upah yang 
sesuai, tunjangan-tunjangan seperti tunjangan kesehatan berupa asuransi kesehatan serta berbagai fasilitas lainnya.Dengan dilaksanakannya program kesejahteraan karyawan secara adil dan merata, maka akan menciptakan lingkungan kerja yang baik serta dapat mewujudkan disiplin kerja yang tinggi. Jika program kesejahteraan karyawan sudah terlaksana dengan baik dan dapat mewujudkan disiplin kerja yang tinggi, maka karyawan pun akan termotivasi untuk menghasilkan produktivitas kerja secara maksimal dan berkualitas (Singh, 2015).Adanya produktivitas kerja karyawan secara maksimal dan berkualitas akan sangat membantu perusahaan yaitu pihak RSUP Sanglah Denpasar dalam mewujudkan tujuan yang ingin dicapai.

\section{Hipotesis}

Hipotesis adalah jawaban sementara terhadap masalah yang sedang diteliti (Sugiyono, 2017). Jawaban sementara ini masih perlu diuji kebenarannya. Oleh karena itu, hipotesis berfungsi sebagai kemungkinan untuk menguji kebenaran suatu teori. Hipotesis sangat penting bagi penelitian karena dengan hipotesis, maka penelitian akan lebih terarah.Dalam penelitian ini, dapat ditarik hipotesis yaitu :

1. Program Kesejahteraan Karyawan berpengaruh signifikan terhadap peningkatan produktivitas kerja karyawan Rumah Sakit Umum Pusat Sanglah Denpasar.

2. Disiplin kerja berpengaruh signifikan terhadap peningkatan produktivitas kerja karyawan Rumah Sakit Umum Pusat Sanglah Denpasar.

3. Faktor disiplin kerja mempunyai pengaruh dominan terhadap peningkatan produktivitas kerja karyawan di Rumah Sakit Umum Pusat Sanglah Denpasar.

\section{METODE PENELITIAN \\ Kerangka Konseptual}

Pada penelitian ini menggunakan 3 (tiga) Variabel yaitu : Program kesejahteraan karyawan (X1), Disiplin kerja (X2), Produktivitas Kerja Karyawan (Y). Adapun pola hubungan variabel tersebut dapat digambarkan sebagai berikut :

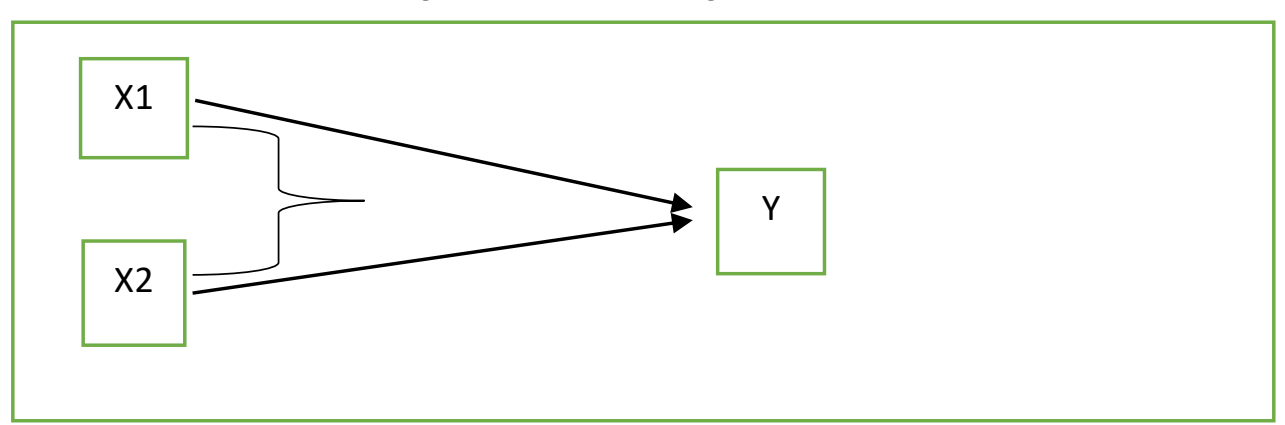

Persamaan regresinya (Sugiyono, 2017) sebagai berikut :

$Y=a+b_{1} X_{1}+b_{2} X_{2}$

Dimana :

$\mathrm{Y}=$ Produktivitas Kerja Karyawan

$\mathrm{a}=$ Nilai konstanta

$b_{1}=$ Koefisien regresi dari $X_{1}$

$\mathrm{b}_{2}=$ Koefisien regresi dari $\mathrm{X}_{2}$

$\mathrm{X}_{1}=$ Program Kesejahteraan Karyawan

$\mathrm{X}_{2}=$ Disiplin Kerja 


\section{Definisi Operasional Variabel \\ Program Kesejahteraan Karyawan}

Dalam penelitian ini, peneliti menggunakan 3 (tiga) variabel yang terdiri dari 2 (dua) variabel bebas dan 1 (satu) variabel terikat, yaitu :

1. Variabel $X_{1}$ adalah Program Kesejahteraan Karyawan, dengan definisi sebagai berikut : program kesejahteraan karyawan adalah bentuk dari keseluruhan program yang diberikan oleh perusahaan atau instansi kepada para karyawannya selama masa pengabdiannya (Purba, 2018). Pada variabel ini terdiri dari 6 (enam) indikator dan 5 skala penilaian : Sangat Setuju (SS) nilai 5, Setuju (S) nilai 4, Cukup Setuju (3), Tidak Setuju (2), Sangat Tidak Setuju

2. Variabel $X_{2}$ adalah Disiplin Kerja, dengan definisi sebagai berikut :

Disiplin Kerja adalah melakukan apa yang sudah disetujui bersama antara pimpinan dengan para pekerja, baik persetujuan tertulis, lisan atau berupa peraturan atau kebiasaan. Disiplin sangat penting karena suatu usaha tidak akan mengalami kemajuan tanpa adanya disiplin dari pihak atasan atau bawahan (Izzah et al., 2016). Pada variabel ini terdiri dari 6 (enam) indikator dan 5 skala penilaian : Sangat Setuju (SS) nilai 5, Setuju (S) nilai 4, Cukup Setuju (3), Tidak Setuju (2), Sangat Tidak Setuju (1),

3. Variabel $\mathrm{Y}$ adalah Produktivitas Kerja Karyawan, dengan definisi sebagai berikut : Produktivitas Kerja Karyawan adalah Perbandingan antara output dengan input, dimana output-nya harus mempunyai nilai tambah dan teknik pengerjaannya yang lebih baik (Siswadi, 2016). Pada variabel ini terdiri dari 6 (enam) indikator dan 5 skala penilaian : Sangat Setuju (SS) nilai 5, Setuju (S) nilai 4, Cukup Setuju (3), Tidak Setuju (2), Sangat Tidak Setuju (1),

\section{Populasi \& Sampel Penelitian}

Populasi dalam penelitian ini adalah karyawan non medis RSUP Sanglah DenpasarAdapun teknik untuk menentukan jumlah sampel menurut Sugiyono (2017), dapat menggunakan rumus sebagai berikut :

1. Teknik penentuan jumlah sampel

$$
s=\frac{P}{\left(P . e^{2}\right)+1}
$$

Dimana :

$$
\begin{array}{ll}
\mathrm{P} & =\text { Populasi } \\
\mathrm{S} & =\text { Sampel } \\
e & =\text { error atau tingkat kesalahan yang diyakini }
\end{array}
$$

Dengan perhitungan sebagai berikut :

$\mathrm{P}=350$ orang karyawan non medis, $e=0,1$

$$
s=\frac{350}{\left(350.0,1^{2}\right)+1}
$$

$s=\frac{350}{4,5}$, berarti $s=77,78 \approx 80$ orang karyawan non medis

Jadi sampel yang diambil dari populasi untuk penelitian adalah 80 orang karyawan non medis RSUP Sanglah Denpasar.

2. Teknik pengambilan sampel

Pada dasarnya dalam penelitian ini peneliti menggunakan teknik pengambilan sampel Nonprobability Sampling dengan menggunakan metode Purposive Sampling yaitu sampel yang dipilih dengan cermat sehingga relevan dengan rancangan penelitian. 


\section{Pengumpulan Data}

Data dan Sumber Data :

Penelitian ini menggunakan data kuantitatif yang merupakan data kualitatif yang diberi skor (skoring). Pada data kuantitatif dalam penelitian ini menggunakan skala pengukuran dengan interval. Untuk melakukan analisis, skala pengukuran ini menggunakan statistik parametric (Sugiyono, 2017). Adapun sumber Data pada penelitian ini yaitu Data primerdidapat dari observasi, kuesioner, maupun interview dengan pihak manajemen dan karyawan RSUP Sanglah Denpasar dan Data sekunder bersumber pada buku-buku literatur terutama mengenai Manajemen Sumber Daya Manusia, Metodologi Penelitian, Profil RSUP Sanglah Denpasar dan buku acuan lainnya.

\section{Teknik Analisis Data}

\section{Uji Instrumen Penelitian}

a. Uji Validitas merupakan hal yang penting bagi suatu alat ukur, karena pengujian ini menunjukkan bahwa instrumen atau alat ukur yang digunakan untuk mengukur suatu konsep benar-benar melakukan fungsinya, yaitu mengukur konsep yang diinginkan.

b. Uji reliabilitas bertujuan untuk memastikan konsistensi alat ukur yang digunakan, sehingga ketika pengukuran kembali dilakukan atas obyek dan teknik yang sama pada waktu yang berbeda, akan memberikan hasil yang sama.

2. Uji hipotesis dipergunakan analisis Regresi Berganda, yang terlebih dahulu dilakukan uji asumsi klasik yang terdiri dari Uji Multikolinieritas, Uji Heteroskedasitisitas, Uji Normalitas Data, Uji t dan Uji F Test dengan persamaan regresi sebagai berikut (Sugiyono, 2017) :

$Y=a+b_{1} X_{1}+b_{2} X_{2}$

Dimana :

$\mathrm{Y}=$ Produktivitas Kerja Karyawan

$\mathrm{a}=$ Nilai konstanta

$\mathrm{b}_{1}=$ Koefisien regresi dari $\mathrm{X}_{1}$

$\mathrm{b}_{2}=$ Koefisien regresi dari $\mathrm{X}_{2}$

$\mathrm{X}_{1}=$ Program Kesejahteraan Karyawan

$\mathrm{X}_{2}=$ Disiplin Kerja

\section{HASIL DAN PEMBAHASAN}

\section{Karakteristik Subyek Penelitian}

Karakteristik responden merupakan sifat yang melekat pada responden atau kondisi demografi responden. Adapun karakteristik yang digunakan adalah yang berhubungan dengan tujuan penelitian. Karakteristik responden karyawan non medis di RSUP Sanglah DenpasarBali yang digunakan dalam penelitian ini antara lain :

1. Jenis Kelamin

Jenis kelamin responden adalah sebagai berikut:

TABEL 3.1

KARAKTERISTIK RESPONDEN BERDASAR JENIS KELAMIN

\begin{tabular}{|c|l|c|c|}
\hline No. & \multicolumn{1}{|c|}{ Jenis Kelamin } & Jumlah & Persentase (\%) \\
\hline 1 & Laki-laki & 28 & 35 \\
\hline 2 & Perempuan & 52 & 65 \\
\hline \multicolumn{2}{|c|}{ Jumlah } & 80 & 100 \\
\hline
\end{tabular}

Sumber : Data Primer diolah 2019

Berdasarkan tabel tersebut dapat diketahui bahwa sebagian besar dari 80 responden berjenis kelamin perempuan, yaitu sebanyak 52 orang atau $65 \%$ dan laki-laki sejumlah 28 orang atau 35\%. Data tersebut menunjukkan bahwa karyawan non medis di Rumah Sakit Umum Pusat Sanglah Denpasar sebagian besar adalah perempuan karena tuntutan pekerjaan memerlukan ketelitian dan kesabaran. 
1. Usia

Usia dapat menggambarkan kematangan atau kedewasaan seseorang untuk bertindak atau berpikir dalam melakukan sesuatu yang terbaik untuk dirinya, pekerjaan maupun orang lain. Berdasarkan karakteristik responden dilihat dari umur responden dapat diketahui bahwa usia merupakan karakteristik yang perlu diperhatikan dalam memahami karyawan, karena faktor umur mempengaruhi perilaku karyawan dalam kehidupan seharihari. Subyek penelitian dikelompokkan berdasarkan kelompok usia sebagai berikut :

TABEL 3.2

KARAKTERISTIK RESPONDEN BERDASAR KELOMPOK USIA

\begin{tabular}{|c|l|c|c|}
\hline No. & \multicolumn{1}{|c|}{ Umur } & Jumlah & Persentase (\%) \\
\hline 1 & $18-23$ tahun & 6 & 7,5 \\
\hline 2 & $24-29$ tahun & 19 & 23,8 \\
\hline 3 & $30-35$ tahun & 17 & 21,3 \\
\hline 4 & $36-40$ tahun & 19 & 23,8 \\
\hline 5 & $>40$ tahun & 19 & 23,8 \\
\hline \multicolumn{2}{|c|}{ Jumlah } & 80 & 100 \\
\hline
\end{tabular}

Sumber : Data primer diolah 2019

Berdasarkan tabel tersebut dapat diketahui bahwa sebagian besar dari 80 responden berumur 24 hingga 29 tahun, 36 hingga 40 tahun dan di atas 40 tahun masimgmasing 19 orang atau 23,8\%. Data tersebut menunjukkan bahwa umur karyawan non medis di RSUP Sanglah Denpasar termasuk relatif merata dalam setiap kelompok umur.

2. Pendidikan

TABEL 3.3

KARAKTERISTIK RESPONDEN BERDASAR PENDIDIKAN

\begin{tabular}{|c|l|c|c|}
\hline No. & \multicolumn{1}{|c|}{ Pendidikan } & Jumlah & Persentase (\%) \\
\hline 1 & SLTA & 16 & 20,0 \\
\hline 2 & Diploma & 15 & 18,8 \\
\hline 3 & S1 & 47 & 58,8 \\
\hline 4 & S2 Jumlah & 2 & 2,5 \\
\hline \multicolumn{2}{|c|}{. } & 80 & 100 \\
\hline
\end{tabular}

Sumber : Data primer diolah 2019

Berdasarkan tabel tersebut dapat diketahui bahwa sebagian besar dari 80 responden memiliki latar belakang pendidikan Sarjana (S1), yaitu sebanyak 47 orang atau $58,8 \%$. Berdasar data tersebut diketahui bahwa karyawan non medis di Rumah Sakit Umum Pusat Sanglah Denpasar memiliki latar belakang pendidikan yang mencukupi untuk mendukung profesinya.

3. Gaji

Besar kecilnya gaji yang diterima karyawan dapat menunjukkan posisi atau jabatan, latar belakang pendidikan dan keahlian seseorang serta senioritas (lama kerja) yang dimiliki, sehingga gaji yang diterima tergantung dari faktor-faktor tersebut. Adapun penghasilan atau gaji yang diterima karyawan per bulan adalah sebagai berikut :

TABEL 3.4

KARAKTERISTIK RESPONDEN BERDASAR PENGHASILAN

\begin{tabular}{|c|c|c|c|}
\hline No. & Penghasilan & Jumlah & Persentase (\%) \\
\hline 1 & $<$ Rp 1.000,000 & 3 & 3,8 \\
\hline 2 & $\operatorname{Rp~1.000.000-Rp~1.500,000~}$ & 35 & 43,8 \\
\hline 3 & $\operatorname{Rp~1.501.000-Rp~2.000,000~}$ & 21 & 26,3 \\
\hline 4 & $\operatorname{Rp~2.001.000-Rp~2.500,000~}$ & 10 & 12,5 \\
\hline 5 & $>\operatorname{Rp~2.500,000}$ & 11 & 13,8 \\
\hline \multicolumn{2}{|c|}{ Jumlah } & 80 & 100 \\
\hline
\end{tabular}

Sumber : Data primer diolah 2019 
Berdasarkan tabel tersebut dapat diketahui bahwa sebagian besar dari 80 responden memiliki penghasilan per bulan sebesar Rp 1.000.000 hingga Rp 1.500,000, yaitu sebanyak 35 orang atau $43.8 \%$. Data tersebut menunjukkan bahwa karyawan non medis di RSUP Sanglah Denpasar memiliki gaji atau penghasilan yang cukup memadai.

\section{Hasil Uji Coba Instrumen}

Adapun hasil uji validitas dan reliabilitas adalah sebagai berikut :

1. Uji Validitas Instrumen

TABEL 3.5

\section{HASIL UJI VALIDITAS INSTRUMEN}

\begin{tabular}{|l|c|c|c|c|c|}
\hline \multirow{2}{*}{ Variabel } & \multirow{2}{*}{ No. Butir } & \multicolumn{2}{|c|}{ Koefisien Korelasi } & \multirow{2}{*}{ Sig. $p$} & \multirow{2}{*}{ Status } \\
\cline { 3 - 5 } & & r hitung & r tabel & 0,000 & Valid \\
& 1 & 0,705 & 0,2199 & 0,000 & Valid \\
& 2 & 0,717 & 0,2199 & 0,000 & Valid \\
& 3 & 0,513 & 0,2199 & 0,000 & Valid \\
& 4 & 0,759 & 0,2199 & 0,000 & Valid \\
\hline Program Kesejahteraan Karyawan & 5 & 0,561 & 0,2199 & 0,000 & Valid \\
\hline & 6 & 0,571 & 0,2199 & 0,000 & Valid \\
& 1 & 0,536 & 0,2199 & 0,000 & Valid \\
& 2 & 0,722 & 0,2199 & 0,000 & Valid \\
& 3 & 0,389 & 0,2199 & 0,000 & Valid \\
& 4 & 0,625 & 0,2199 & 0,000 & Valid \\
& 5 & 0,611 & 0,2199 & 0,000 & Valid \\
\hline Produktivitas Kerja Karyawan & 6 & 0,667 & 0,2199 & 0,000 & Valid \\
& 2 & 0,428 & 0,2199 & 0,000 & Valid \\
& 3 & 0,418 & 0,2199 & 0,000 & Valid \\
& 4 & 0,720 & 0,2199 & 0,000 & Valid \\
& 5 & 0,514 & 0,2199 & 0,000 & Valid \\
\hline
\end{tabular}

Sumber : Data primer diolah 2019

Berdasarkan hasil uji validitas tersebut dapat diketahui bahwa dari 18 butir pertanyaan yang diuji pada masing-masing variabel, secara keseluruhan butir pertanyaan dinyatakan valid karena memiliki nilai koefisien korelasi $(r)$ hitung lebih besar dari $r$ tabel 0,2199 (Sugiyono, 2017) atau signifikansi yang dihasilkan kurang dari 0,05.

2. Uji Reliabilitas Instrumen

TABEL 3.6

HASIL UJI RELIABILITAS INSTRUMEN

\begin{tabular}{|l|c|c|c|}
\hline \multicolumn{1}{|c|}{ Variabel } & Koefisien Reliabilitas & Alpha & Status \\
\hline Program Kesejahteraan Karyawan & 0,741 & 0,6 & Reliabel \\
\hline Disiplin Kerja & 0,691 & 0,6 & Reliabel \\
\hline Produktivitas Kerja Karyawan & 0,617 & 0,6 & Reliabel \\
\hline
\end{tabular}

Sumber : Data primer diolah 2019

Berdasarkan hasil pengujian tersebut dapat diketahui bahwa masing-masing variabel yang diuji memiliki koefisien reliabilitas (Alpha Cronbach) melebihi 0,6, dengan demikian instrumen yang digunakan dalam penelitian dinyatakan reliabel.Setelah pengujian validitas dan reliabilitas dilakukan dan diketahui butir-butir yang diuji dinyatakan valid dan masing-masing variabel instrumen reliabel, maka instrumen dapat digunakan untuk pengambilan data penelitian.

\section{Analisis Data}

1. Regresi Linier Berganda

Hasil perhitungan adalah sebagai berikut : 
TABEL 3.7

HASIL ANALISIS REGRESI LINIER BERGANDA

\begin{tabular}{|c|c|c|c|c|}
\hline & B & Beta & $t$ & Sig. $p$ \\
\hline $\begin{array}{ll}\text { Konstanta } & \text { (a) } \\
\end{array}$ & 3,054 & & & \\
\hline $\begin{array}{l}\text { Program Kesejahteraan Karyawan } \\
\left(b_{1}\right)\end{array}$ & 0,403 & 0,367 & 3,946 & 0,000 \\
\hline Disiplin Kerja $\quad\left(b_{2}\right)$ & 0,445 & 0,430 & 4,618 & 0,000 \\
\hline $\begin{array}{l}\mathrm{R} \\
\mathrm{R}^{2} \\
\text { Adjusted } \mathrm{R}^{2} \\
\mathrm{~F}\end{array}$ & & $\begin{array}{r}0,672 \\
0,452 \\
0,438 \\
31,75\end{array}$ & & 0,000 \\
\hline
\end{tabular}

Sumber : Data primer diolah 2019

Berdasarkan hasil tersebut, maka persamaan regresi yang dihasilkan adalah :

Artinya :

$$
Y=3,054+0,403 X_{1}+0,445 X_{2}
$$

a. Konstanta (a) sebesar 3,054 artinya jika tidak ada variabel bebas atau jika tidak ada program kesejahteraan karyawan dan disiplin kerja (kesejahteraan karyawan dan disiplin kerja sama dengan nol), maka produktivitas kerja karyawan sebesar 3,054 poin.

b. Koefisien regresi variabel program kesejahteraan karyawan $\left(b_{1}\right)$ sebesar 0,403 artinya jika program kesejahteraan karyawan bertambah 1 poin (karena bertanda positif), maka produktivitas kerja karyawan akan meningkat sebesar 0,403 poin dengan anggapan variabel lain konstan.

c. Koefisien regresi variabel disiplin kerja $\left(b_{2}\right)$ sebesar 0,445 artinya jika disiplin kerja meningkat 1 poin (karena bertanda positif), maka produktivitas kerja karyawan akan meningkat sebesar 0,445 poin dengan anggapan variabel lain konstan.

\section{Hasil Uji Hipotesis}

1. Uji t

Hasil uji t berdasarkan Tabel 3.7 adalah sebagai berikut :

a. Pengaruh Program Kesejahteraan Karyawan Terhadap Peningkatan Produktivitas Kerja Karyawan RSUP Sanglah Denpasar

Berdasar hasil hitungan diketahui bahwa t hitung sebesar 3,946 lebih besar dari t tabel 1,9913 $(3,946>1,9913)$ dengan signifikansi $0,000<0,05$, dengan demikian Ho ditolak atau hipotesis alternatif $(\mathrm{Ha})$ yang diajukan bahwa program kesejahteraan karyawan berpengaruh terhadap peningkatan produktivitas kerja karyawan di RSUP Sanglah Denpasar terbukti. Jika program kesejahteraan karyawan semakin ditingkatkan, maka produktivitas kerja pun semakin meningkat. Secara grafis penerimaan dan penolakan hipotesis adalah sebagai berikut :

b. Pengaruh Disiplin Kerja Terhadap Produktivitas Kerja Karyawan Non Medis di RSUP Sanglah Denpasar

Berdasar hasil hitungan diketahui bahwa t hitung sebesar 4,618 lebih besar dari $t$ tabel 1,9913 $(4,618>1,9913)$ dengan signifikansi $0,000<0,05$, dengan demikian Ho ditolak atau hipotesis alternatif (Ha) yang diajukan bahwa disiplin kerja berpengaruh terhadap peningkatan produktivitas kerja karyawan di Rumah Sakit Umum Pusat Sanglah Denpasar terbukti. Jika disiplin kerja diterapkan dengan baik dan benar, maka produktivitas kerja semakin meningkat.

2. Uji F

Berdasar hasil hitungan diketahui bahwa $\mathrm{F}$ hitung sebesar 31,754 lebih besar dari $\mathrm{F}$ tabel $3,963(31,754>3,963)$ dengan signifikansi $0,000<0,05$, dengan demikian Ho ditolak atau hipotesis alternatif $(\mathrm{Ha})$ yang diajukan bahwa program kesejahteraan karyawan dan disiplin kerja berpengaruh terhadap peningkatan produktivitas kerja karyawan di RSUP Sanglah Denpasar terbukti. 
3. $\quad$ Uji $R^{2}$ (Determinasi)

Koefisien determinasi $\left(R^{2}\right)$ pada intinya mengukur seberapa jauh kemampuan model dalam menerangkan variasi variabel dependen (Sugiyono, 2017). Hasil dapat dilihat pada Tabel 3.7 yang menunjukkan bahwa korelasi simultan yang dihasilkan ( $R$ ) variabel-variabel program kesejahteraan karyawan dan disiplin kerja terhadap produktivitas kerja sebesar 0,672 ,dengan demikian koefisien determinasi $\left(\mathrm{R}^{2}\right)$ sebesar 0,452 sedangkan Adjuster $R$ square hasil regresi sebesar 0,438.Berdasarkan hasil tersebut diketahui bahwa koefisien determinasi yang digunakan dalam penelitian ini adalah $R$ square karena menggunakan dua variabel bebas dalam model regresi, artinya $45,2 \%$ produktivitas kerja karyawan Non Medis di Rumah Sakit Umum Pusat Sanglah Denpasar dipengaruhi oleh program kesejahteraan karyawan dan disiplin kerja sedangkan $54,8 \%$ sisanya dipengaruhi oleh variabel lain yang tidak diteliti.

4. Variabel Dominan

Berdasarkan hasil analisis regresi linier berganda sebagaimana termuat dalam Tabel 3.7, maka dapat diketahui bahwa variabel disiplin kerja $\left(\mathrm{X}_{2}\right)$ merupakan variabel yang dominan berpengaruh terhadap peningkatan produktivitas kerja (Y) karyawan RSUP Sanglah Denpasar dengan koefisien beta yang dihasilkan sebesar 0,430.

\section{A. Uji Asumsi Klasik}

Uji asumsi klasik merupakan tahapan yang penting dilakukan dalam proses analisis regresi. Apabila tidak terdapat gejala asumsi klasik diharapkan dapat dihasilkan model regresi yang handal sesuai dengan kaidah BLUE (Best Linier Unbiased Estimator), yang menghasilkan model regresi yang tidak bias dan handal sebagai penaksir (Sugiyono, 2017). Uji asumsi klasik juga berguna untuk melengkapi uji statistik yang telah dilakukan yaitu uji t, uji $F$ dan koefisien determinasi.

1. Uji Multikolinieritas

TABEL 3.8

HASIL UJI MULTIKOLINIERITAS

\begin{tabular}{|l|c|c|}
\hline \multicolumn{1}{|c|}{ Variabel } & \multicolumn{2}{|c|}{ Collinearity Statistics } \\
\cline { 2 - 3 } & Tolerance & VIF \\
\hline Program Kesejahteraan Karyawan & 0,823 & 1,216 \\
\hline Disiplin Kerja & 0,823 & 1,216 \\
\hline
\end{tabular}

Sumber : Data primer diolah 2019

Berdasarkan hasil tersebut dapat diketahui bahwa nilai VIF variabel pemenuhan program kesejahteran karyawan sebesar 1,216 (Tolerance 0,823), dan variabel disiplin kerja sebesar 1,216 (Tolerance 0,823) (Tolerance 0,823) dimana nilai VIF tersebut kurang dari 5, dengan demikian tidak ada multikolinieritas pada model regresi yang digunakan.

\section{Uji Heteroskedastisitas}

Untuk melihat ada tidaknya gejala heteroskedastisitas digunakan grafik scatter-plot, yaitu dengan melihat antara ZPRED (nilai prediksi variabel bebas) dan SRESID (residualnya) hasil regresi. Hasil scatter-plot adalah sebagai berikut : 


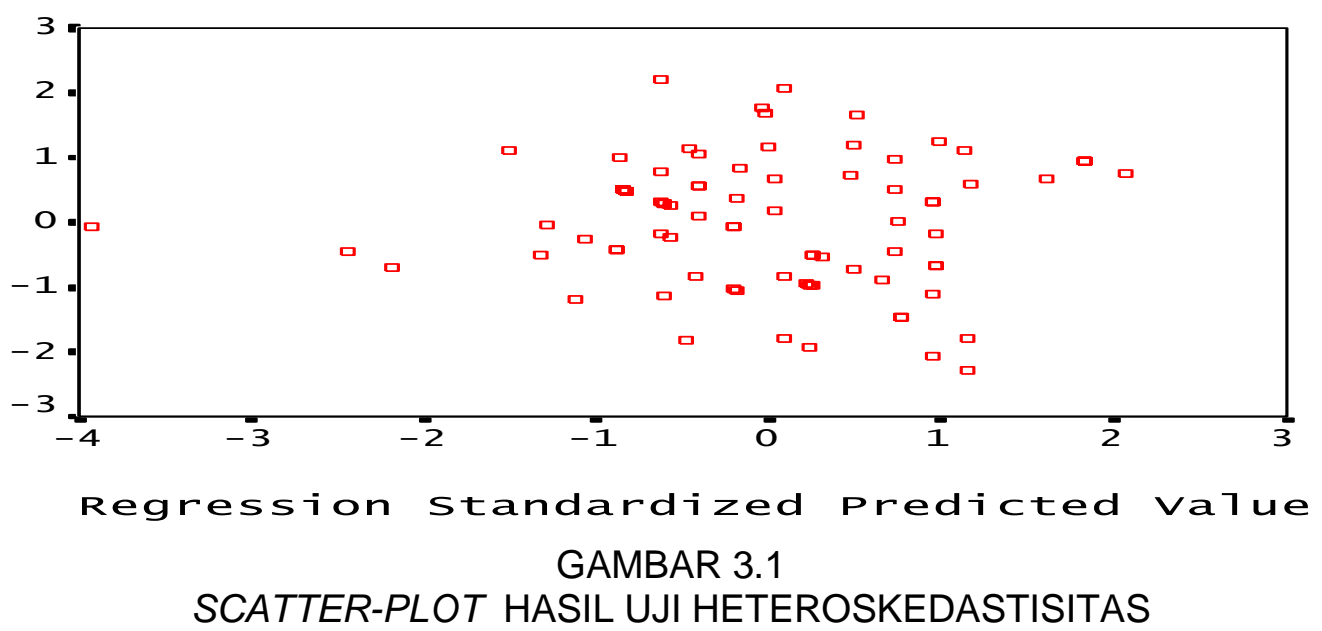

Berdasarkan scatter-plot tersebut, tampak tidak berpola dan tidak beraturan baik di atas maupun di bawah angka nol (0) sumbu $Y$ maupun sebelah kanan dan kiri sumbu $X$ sehingga dapat disimpulkan bahwa model regresi yang digunakan tidak ada gejala heteroskedastisitas.

3. Uji Normalitas Data

Besarnya nilai signifikansi Kolmogorov smirnov test untuk variabel-variabel berikut ini, yaitu untuk :

a. Variabel program kesejahteraan karyawan $\left(X_{1}\right)$ adalah 0,169 (sig. $\left.p>0,05\right)$

b. Variabel disiplin kerja $\left(X_{2}\right)$ sebesar 0,084 (sig. $p>0,05$ )

c. Variabel produktivitas kerja karyawan sebesar 0,081 (sig. $p>0,05$ ).

Berdasarkan hasil tersebut dapat diketahui bahwa sebaran data pada masingmasing variabel berdistribusi normal.

\section{SIMPULAN DAN SARAN}

B. Simpulan

Berdasarkan hasil analisis data serta hasil pembahasan dari data-data yang diperoleh dari Rumah Sakit Umum Pusat Sanglah Denpasar, maka peneliti mendapatkan kesimpulan sebagai berikut :

1. Hipotesis yang menyatakan bahwa Program Kesejahteraan Karyawan berpengaruh signifikan terhadap peningkatan produktivitas kerja karyawan Rumah Sakit Umum Pusat Sanglah Denpasar ternyata terbukti. Dengan demikian, apabila program kesejahteraan karyawan semakin ditingkatkan, maka produktivitas kerja karyawan pun semakin meningkat.

2. Hipotesis yang menyatakan bahwa Disiplin kerja berpengaruh signifikan terhadap peningkatan produktivitas kerja karyawan Rumah Sakit Umum Pusat Sanglah Denpasar ternyata terbukti. Jika disiplin kerja diterapkan dengan baik dan benar, maka produktivitas kerja pun semakin meningkat.

4. Hipotesis yang menyatakan bahwa Faktor disiplin kerja mempunyai pengaruh dominan terhadap peningkatan produktivitas kerja karyawan di Rumah Sakit Umum Pusat Sanglah Denpasar ternyata terbukti.

\section{B. Saran}

Berdasarkan kesimpulan di atas, maka peneliti dapat mengemukakan beberapa saran bagi pihak Rumah Sakit Umum Pusat Sanglah Denpasar sebagai berikut :

1. Bagi pihak Rumah Sakit Umum Pusat Sanglah Denpasar, adanya program kesejahteraan bagi karyawan sangat berguna dalam memberikan motivasi agar karyawan dapat meningkatkan produktivitas kerjanya. Oleh karena itu, sebaiknya 
program kesejahteraan karyawan dapat dilaksanakan secara adil dan merata sesuai dengan peraturan yang berlaku, misalnya : dilihat dari masa kerja karyawan bersangkutan, tingkat pendidikan, prestasi, dan lainnya.

2. Bagi pihak RSUP Sanglah Denpasar-Bali, hendaknya karyawan lebih disiplin dalam menggunakan waktu saat bekerja agar dapat meningkatkan produktivitas kerja dalam melayani masyarakat.

3. Sebaiknya disiplin kerja yang telah ada dapat dipertahankan atau bahkan dapat lebih ditingkatkan. Penggunaan absensi dengan menggunakan tanda tangan dirasakan kurang efektif, karena selama peneliti melakukan penelitian, peneliti melihat penggunaan absensi dengan tanda tangan dapat diwakilkan oleh teman sekerja. Peneliti menyarankan sebaiknya menggunakan beberapa alternatif penggunaan absensi selain tanda tangan yaitu dengan menggunakan foto wajah atau sidik jari dari karyawan bersangkutan dengan tujuan produktivitas kerja dapat dilakukan secara maksimal.

\section{Daftar Pustaka}

Cecilia, S., dan Lucky, OH. 2015. Pengaruh Disiplin, Motivasi dan Semangat Kerja Terhadap Produktivitas Kerja Pegawai Dinas Pendapatan Daerah Kota Manado. Jurnal EMBA, Vol.3 No.2 Juni, Hal. 639-649

Harliawan, H.,Yasa,M.,Heny,M. 2017. Pengaruh Kompensasi, Pendidikan dan Program Kesejahteraan Terhadap Produktivitas Kerja Wartawan di Provinsi Bali. E-Jurnal Ekonomi dan Bisnis Universitas Udayana 6.7 : 2697-2730

Izzah, N., dan Ardiani, I. 2016. Pengaruh Kompensasi dan Disiplin Kerja Terhadap Produktivitas Kerja Karyawan Pada Mechanical Division PT.Mulia Makmur Elektrikatama. BIJAK, Volume XIII, No.02, September.

Lukitasari, Lina. 2016. Pengaruh Pelaksanaan Program Kesejahteraan Jaminan Sosial, Insentif dan Pelatihan Kerja Terhadap Produktivitas Karyawan CV.ljo Geneng Ngawi. The 5th FIPA (Forum Ilmiah Pendidikan Akuntansi) Program Studi Pendidikan Akuntansi - FPIPS IKIP PGRI, Madiun.

Malayu, Hasibuan. 2018. Manajemen Sumber Daya Manusia. Jakarta : Bumi Aksara

M.Manullang. 2015. Dasar-dasar manajemen. Yogyakarta : Gadjah Mada University Press

Muslimin, RM., Kojo, C., dan Lucky, OH. 2016. Analisis Pelatihan Motivasi Dan Disiplin Kerja Terhadap Produktivitas Kerja Pegawai pada PT.Pos dan Giro Manado. Jurnal EMBA, Vol.4 No.2 Juni , Hal. 187-198

Purba, H. 2018. Pengaruh Program Kesejahteraan Terhadap Produktivitas Kerja Pegawai Pada Dinas Pekerjaan Umum Kabupaten Toba Samosir. Jurnal STINDO Profesional, Volume IV, Nomor 4, Mei (ISSN : 2443-0536)

Radito, A. 2016. Analisis Pengaruh Disiplin kerja, Lingkungan kerja, dan Jaminan Sosial Terhadap Produktivitas Kerja Pegawai. Sekolah Tinggi IImu Ekonomi IEU Yogyakarta. JBMA - Vol.III, No.2, September. 
Saleh, AR., dan Utomo, H. 2018. Pengaruh Disiplin kerja, Motivasi kerja, Etos kerja dan Lingkungan kerja Terhadap Produktivitas Kerja Karyawan Bagian Produksi di PT.Inko Jaya Semarang. Jurnal Among Makarti, Vol.11 No.21, Juli

Singh, Sweta. 2015. Effectiveness Of Employee Welfare In Maruti Suzuki In Varanasi Region. Journal of Management Research and Analysis, April - Juni 2015;2(2):150-161

Siswadi, Yudi. 2016. Pengaruh Pelatihan dan Disiplin Terhadap Produktivitas Kerja Karyawan pada PT.Jasa Marga Cabang (Belmera) Medan. Jurnal IImiah Manajemen dan Bisnis Vol.17, No.01, April 2016. ISSN : 1693 - 7619 (Print) http://jurnal.umsu.ac.id

Sugiyono . 2017. Metode Penelitian : Kuantitatif . Kualitatif dan $R \& D(a$.) Bandung : Alfabeta. 
Jurnal Prospek, Vol. 1 No. 2, Bulan Desember Tahun 2019

P-ISSN: 2685-5526 